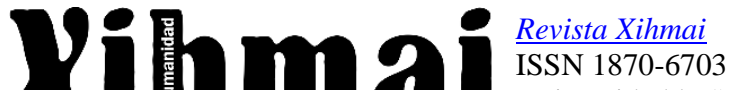 Universidad la Salle Pachuca http://doi.org/10.37646/xihmai.v16i31.515
}

\section{PRÁCTICAS DE ENSEÑANZA EN LA MODALIDAd DOMICILIARIA: CRUCES CON LA EDUCACIÓN RURAL Y EL USO DE TIC}

Teaching Practices in Domiciliary Education: RELATIONS WITH RURAL EDUCATION AND ICT USES

María Rosa Brumat ${ }^{a}$ / Diego Agustín Moreiras ${ }^{b}$

\section{Nota sobre los autores:}

${ }^{a}$ Doctora en Estudios Sociales de América Latina y Lic. en Ciencias de la Educación, ambas por la Universidad Nacional de Córdoba.

${ }^{\mathrm{b}}$ Magister en Investigación Educativa y Lic. en Comunicación Social, ambas por la Universidad Nacional de Córdoba.

Proyecto con subsidio de la Secretaría de Políticas Universitarias, Ministerio de Educación de la Nación (Argentina). Los autores no tienen ningún conflicto de interés al haber hecho esta investigación.

Remita cualquier duda sobre este artículo al siguiente correo electrónico: mariarosabru77@gmail.com

Recibido: 18/11/2020 Corregido: 16/03/2021 Aceptado: 1/04/2021 
Xihmai 40 
María Rosa Brumat/Diego Agustín Moreiras Prácticas de enseñanza en la modalidad domiciliaria:

Cruces con la educación rural y el uso de TIC Revista Xihmai XVI (31), 39-74, enero-junio 2021

\title{
PRÁCTICAS DE ENSEÑANZA EN LA MODALIDAD DOMICILIARIA: CRUCES CON LA EDUCACIÓN RURAL Y EL USO DE TIC
}

\author{
Teaching Practices in DOMICILIARY EdUCATION: \\ RELATIONS WITH RURAL EDUCATION AND ICT USES
}

\section{Resumen}

En este trabajo presentamos avances de una investigación en curso desarrollada y financiada desde la Universidad Nacional de Chilecito, desde junio de 2019 y hasta diciembre de 2020. En esta oportunidad presentamos algunas reflexiones en torno a las prácticas docentes de una maestra de nivel primario de la modalidad de Educación Domiciliaria y Hospitalaria sobre la configuración de su trabajo pedagógico con alumnos en contextos rurales. A través de una estrategia metodológica cualitativa de corte etnográfico nos interesa, en primer lugar, la articulación entre modalidades (rural y domiciliaria) que se da en las prácticas de enseñanza de esta maestra. Luego, el uso de TIC en las prácticas de enseñanza de la docente en contextos rurales y como parte de su desempeño en la modalidad domiciliaria; la conceptualización que ella propone para estas prácticas y los aportes que realiza, desde un hacer situado, a la noción de "aula ampliada". Finalmente, cerramos este escrito con algunas reflexiones a modo de desafíos en la tarea de enseñar (y aprender) que consideramos resultan pertinentes también para otras modalidades educativas.

Palabras clave: prácticas de enseñanza, educación domiciliaria, educación rural, tecnologías de la información y la comunicación, aula ampliada.

\section{Summary}

In this paper we present advances of a research developed and funded by the Universidad Nacional de Chilecito, from june 2019 until december 2020. This time we present some reflections on the teaching practices of a primary level teacher of the Domiciliary and Hospital Education modality on the configuration of her pedagogical work with students in rural contexts. We are interested, first of all, in the articulation between modalities (rural and domiciliary) that occurs in the teaching practices surveyed. We also attend to the uses of ICT in the teaching practices of this teacher in rural areas within the domiciliary education; then the conceptualization that she proposes for those practices and the contributions that she makes from its situated practice to the notion of "extended classroom". Finally, we want to close this writing with some reflections arising from the work of this teacher in the home modality, as challenges in the task of teaching (and learning) that we consider are also pertinent for other modalities. 
María Rosa Brumat/Diego Agustín Moreiras Prácticas de enseñanza en la modalidad domiciliaria:

Cruces con la educación rural y el uso de TIC Revista Xihmai XVI (31), 39-74, enero-junio 2021

Keywords: teaching practices, information and communication technologies, domiciliary and hospital education, rural education, extended classroom.

\section{Introducción}

En el presente trabajo nos proponemos compartir resultados parciales de una investigación aprobada y financiada por la Universidad Nacional de Chilecito, de la provincia de La Rioja, Argentina, iniciada en junio de 2019. ${ }^{1}$ Los avances que presentamos están centrados en las prácticas de enseñanza de una maestra de nivel primario que se desempeña en la modalidad domiciliaria y hospitalaria. Nos interesa mostrar avances y someter a la discusión el trabajo de esta docente, a quien llamaremos $\mathrm{Ana}^{2}$, en relación con dos tópicos: a) sus prácticas pedagógicas en el cruce entre la modalidad domiciliaria y la modalidad rural (ya que las/os estudiantes con quienes trabaja se encuentran matriculadas/os en escuelas rurales), y b) las estrategias y decisiones que asume cotidianamente como parte sus prácticas docentes en el trabajo con Tecnologías de la Información y la Comunicación (TIC) y dispositivos digitales. Así, presentamos en primer lugar el encuadre legal que da marco a la modalidad domiciliaria (y a la rural) a nivel nacional y provincial, las definiciones conceptuales centrales de nuestra investigación en torno a las prácticas docentes y al trabajo con TIC y dispositivos digitales; en segundo lugar, damos cuenta de nuestra perspectiva metodológica; en tercer lugar, compartimos resultados parciales a partir del trabajo de campo realizado, así como de algunas discusiones surgidas en la investigación: entre esos resultados, nos detenemos en la forma en la que la propia docente categoriza su práctica (como de "aula extendida"), las divergencias que surgen entre la definición de esta noción y las prácticas efectivamente llevadas adelante por Ana, más allá de otros conceptos potencialmente relacionados con ella. Finalmente, socializamos reflexiones a las que hemos arribado a partir de la experiencia investigada y a la luz del escenario en el cual escribimos este artículo.

\footnotetext{
${ }^{1}$ Proyecto de Investigación "Educación rural y educación de jóvenes y adultos en la provincia de La Rioja. Un estudio de caso en el Departamento Chilecito". Directora: Dra. María Rosa Brumat. Departamento de Ciencias de la Educación, Universidad Nacional de Chilecito. Aprobado por Resol. Rectoral $N^{\circ} 883 / 18$. Proyecto con subsidio de la Secretaría de Políticas Universitarias, Ministerio de Educación de la Nación.

${ }^{2}$ Seguimos en este sentido criterios comunes en trabajos de corte etnográfico: reservamos la identidad de la docente y de las instituciones con las que trabaja, a partir de asignarles un nombre de fantasía.
}

Xihmai 42 
María Rosa Brumat/Diego Agustín Moreiras Prácticas de enseñanza en la modalidad domiciliaria:

Cruces con la educación rural y el uso de TIC Revista Xihmai XVI (31), 39-74, enero-junio 2021

\section{Marco teórico}

\subsection{Educación y modalidades educativas en Argentina}

En Argentina, desde el año 2006, la Ley de Educación Nacional No. 26.206 concibe a la educación como un derecho y al Estado nacional como el garante responsable de responder por esto. Esta ley establece la escolaridad obligatoria desde el nivel inicial (salas de 4 y 5 años) hasta el término de la educación secundaria (18 años). Organiza el sistema educativo argentino en cuatro niveles (inicial, primario, secundario y superior) y ocho modalidades (educación rural, de jóvenes y adultos, artística, especial, técnico profesional, contextos de privación de la libertad, intercultural y bilingüe). Las modalidades educativas son:

Aquellas opciones organizadas y/o curriculares de la educación común, dentro de uno o más niveles educativos, que procuran dar respuesta a requerimientos específicos de formación y atender particularidades de carácter permanente o temporal, personales y/o contextuales, con el propósito de garantizar la igualdad en el derecho a la educación y cumplir con las exigencias legales, técnicas y pedagógicas de los diferentes niveles educativos. (Ley de Educación Nacional No. 26.206, Art. 17)

Esta ley establece que, entre las mencionadas, la modalidad domiciliaria y hospitalaria tiene como objetivo promover la igualdad de oportunidades de las/os estudiantes que se encuentran imposibilitados de continuar con sus trayectorias escolares por razones de salud. Por lo tanto, toda vez que un/a estudiante de los niveles obligatorios, matriculado previamente en alguna escuela de modalidad común, rural u otra, se ve imposibilitado por cuestiones de salud para continuar con su trayectoria escolar, intervienen docentes de la modalidad hospitalaria (en el caso de internaciones) y domiciliaria para dar continuidad a sus estudios (Ley de Educación Nacional No. 26.206, 2006, Art. $60)^{3}$

La Ley de Educación Nacional No. 26.206 expresa, asimismo, que la Educación Rural es la modalidad del Sistema Educativo de los niveles de Educación Inicial, Primaria y Secundaria destinada a garantizar el

\footnotetext{
${ }^{3}$ Para profundizar específicamente en la historia de la modalidad hospitalaria en Argentina puede consultarse, por ejemplo, García Álvarez (2014).
}

Xihmai 43 
María Rosa Brumat/Diego Agustín Moreiras Prácticas de enseñanza en la modalidad domiciliaria:

Cruces con la educación rural y el uso de TIC Revista Xihmai XVI (31), 39-74, enero-junio 2021

cumplimiento de la escolaridad obligatoria a través de formas adecuadas a las necesidades y particularidades de la población que habita en zonas rurales (Art. 49). El fundamento de esta modalidad, por lo tanto, está anclado en los espacios y territorios en los cuales las escuelas se encuentran situadas.

Por su parte, la Ley de Educación de la provincia de La Rioja No. 8.678 del año 2009 reconoce, al igual que la Ley Nacional, a la Educación Domiciliaria y Hospitalaria y a la Educación Rural como modalidades del sistema educativo. Con respecto a la Educación Domiciliaria y Hospitalaria establece que es,

la modalidad del Sistema Educativo destinada a atender a todos los niños/as y jóvenes, del Nivel Inicial, Primario y Secundario que, por razones de salud, u otras debidamente justificadas, se ven imposibilitados de asistir con regularidad a una Institución Educativa por períodos de treinta (30) días corridos o más. Esta modalidad garantizará la igualdad de oportunidades a los niños/as, permitiendo la continuidad de los estudios y la reinserción en el sistema común, cuando ello sea posible. (Ley de Educación de la provincia de La Rioja, Art. 74)

Sumado a lo anterior, agrega que, "el Servicio Educativo de Atención Domiciliaria y Hospitalaria se prestará en los domicilios de los alumnos/as y en los Centros de Salud donde se encuentren internados" (Ley de Educación de la provincia de La Rioja, Art. 76).

El reconocimiento de las modalidades ha planteado un avance importante en términos de política educativa en Argentina, desde el año 2006 respecto a las políticas educativas de la década de los 90. Al considerar a la Educación Domiciliaria y Hospitalaria y a la educación rural como modalidades del sistema, se reconoce la especificidad de los procesos educativos en estos espacios, la necesidad de pensar formas organizativas y pedagógicas que den respuestas a las necesidades de los sujetos en estos contextos y a pensar la necesidad de formación para los docentes que se desempeñan en estas modalidades.

El ingreso de estudiantes a la modalidad Domiciliaria y Hospitalaria es una estrategia para garantizar las trayectorias escolares de estos sujetos que por algún motivo atraviesan una situación de enfermedad que no les permite continuar/completar su escolaridad obligatoria. Las trayectorias escolares de estas/os alumnas/os están condicionadas al curso y desarrollo de sus enfermedades y tratamientos, lo que va configurando formas particulares de Xihmai 44 
María Rosa Brumat/Diego Agustín Moreiras Prácticas de enseñanza en la modalidad domiciliaria:

Cruces con la educación rural y el uso de TIC Revista Xihmai XVI (31), 39-74, enero-junio 2021

atravesar la modalidad según los casos particulares. Los cambios en las situaciones de salud y enfermedad se constituyen en desafíos para la modalidad, pues obligan a pensar y diseñar formas y dispositivos según las características de cada caso para asegurar la continuidad de sus trayectorias.

La Educación Domiciliaria y Hospitalaria debe garantizar la continuidad educativa de los alumnos, es así como las escuelas se constituyen en ese espacio que permite ver garantizado el derecho a la educación de calidad y en un espacio de igualdad. En este sentido, la modalidad debe pensarse como una opción transitoria, sin desconocer que existen algunos niños y jóvenes que transitan toda o casi toda su escolaridad en ella.

Las jurisdicciones han generado distintos dispositivos que apuntan a dar respuesta a la demanda de educación y, por lo tanto, podemos encontrar distintas formas organizativas que asumen dos formatos básicos: escuelas y servicios educativos. La modalidad en la que Ana se desempeña puede ser entendida como escuelas hospitalarias y servicios domiciliarios. En ellos, es posible sostener intervenciones temporalmente acotadas, al final de las cuales el/la estudiante regresa a la escuela en la cual se encontraba matriculado/a originalmente o se puede prolongar el servicio el tiempo necesario, de acuerdo a las razones de salud antes invocadas. Lo importante, no obstante, es que el/la estudiante, en términos administrativos, es alumno/a de una institución escolar en la cual se encuentra previamente inscrita/o. En tanto modalidad del sistema educativo, las instituciones (y servicios) de la Educación Domiciliaria y Hospitalaria pertenecen al sistema, al igual que las/os alumnas/os y docentes, a pesar de que los encuentros de enseñanza y aprendizaje tienen lugar en otros contextos diferentes (el hospital y el domicilio) a la escuela común.

La Educación Domiciliaria alcanza a la atención educativa de los alumnos que se encuentran en estado de reposo domiciliario porque están atravesando una situación de enfermedad que les impide asistir a la escuela. De esta manera, el hogar, el domicilio de cada alumna/o se constituye en un aula escolar domiciliaria, donde el docente lleva a cabo la escolarización. Los docentes van en búsqueda de las/os alumnas/os en sus hogares. Cada familia imprime características particulares según los usos y espacios de sus habitantes. Este hogar es un lugar de intimidad de la familia, esto implica para la/el docente ser respetuoso de esa intimidad para poder establecer un vínculo que favorezca la actividad educativa. 
María Rosa Brumat/Diego Agustín Moreiras Prácticas de enseñanza en la modalidad domiciliaria:

Cruces con la educación rural y el uso de TIC Revista Xihmai XVI (31), 39-74, enero-junio 2021

Así, conformar una escuela en un contexto domiciliario y constituirse como docente en ese espacio conlleva verdaderos desafíos debido a la situación más o menos transitoria de enfermedad del/de la estudiante, pero también debido a la necesidad de atender al mismo tiempo al entorno familiar y doméstico en el cual esta aula tiene lugar.

En el documento Lineamientos Generales de la modalidad hospitalaria y domiciliaria (2010) se explicita que las dos principales variables de análisis de estos servicios educativos son el diagnóstico médico de las/os estudiantes y la permanencia, es decir, la duración del tratamiento. El docente deberá atender estas dimensiones a partir de un trabajo particular con cada estudiante, en un caso por caso que procurará garantizar, entre los objetivos específicos: "mantener la continuidad de los aprendizajes escolares y mantener el vínculo con la escuela de origen del alumno en pos de su reinserción", y entre los subsidiarios: "favorecer los procesos de relación y socialización de los alumnos, necesarios para su desarrollo, y proyectar al alumno hacia el futuro y la vida." (Lineamientos Generales de la Modalidad Educación hospitalaria y domiciliaria, 2010, p. 9). Como mostraremos más adelante, estos objetivos vinculados con la continuidad de la trayectoria escolar de las/os estudiantes y el sostén de los vínculos con la escuela de origen son especialmente pertinentes para dar cuenta de la experiencia analizada.

María Mercedes Gómez (2011) recupera estos lineamientos y pone especial énfasis en las cuestiones metodológicas de las propuestas de enseñanza y en su necesaria preparación artesanal, caso por caso:

La situación de enfermedad hará necesaria, en algunos casos, la adecuación de los contenidos curriculares: metodologías, estrategias y técnicas. Las estrategias pedagógicas se diseñarán para el "caso por caso" según las variables de análisis: permanencia y diagnóstico. A menor permanencia más estrecha es la relación y coordinación con la escuela de origen. (...) En ambos contextos (aula hospitalaria o aula domiciliaria) hablamos de una enseñanza a medida pues el trabajo educativo es personalizado y se realiza según lo expresado anteriormente, en un campo de intersección de discursos: discurso pedagógico, médico, sanitario, socioeconómico, subjetivo, etc., donde estos aspectos asociados a la historia singular del alumno, definen las características y condicionamientos del servicio. Las estrategias pedagógicas se diseñan para el "caso por caso", respetuosas de la singularidad y necesidades del alumno. (p. 15 y 17) (cursivas nuestras)

Xihmai 46 
María Rosa Brumat/Diego Agustín Moreiras Prácticas de enseñanza en la modalidad domiciliaria:

Cruces con la educación rural y el uso de TIC Revista Xihmai XVI (31), 39-74, enero-junio 2021

Esta característica de la construcción de las propuestas de enseñanza ("artesanalmente", en un "caso por caso") funciona como una constante en la modalidad y la encontraremos también en las prácticas que analizamos.

Como ya hemos mencionado, si bien estos servicios educativos hospitalarios y domiciliarios comprenden una única modalidad, involucran propuestas de enseñanza y demandan prácticas docentes que tienen sus particularidades, de acuerdo con el espacio en el que se desarrollen y a las/os estudiantes con quienes trabajan. Por lo tanto, en este artículo daremos cuenta de qué manera las estrategias metodológicas que Ana implementa responden a las necesidades y particularidades de cada estudiante. A tal fin, el trabajo con TIC se vuelve fundamental.

\subsection{Prácticas docentes: más que propuestas de enseñanza}

A continuación, definiremos de qué manera entendemos en este artículo la noción de prácticas docentes y luego haremos lo propio con el trabajo con TIC en la modalidad hospitalaria y domiciliaria.

Hipotetizamos que en la construcción de las prácticas se implican las trayectorias socioeducativas y laborales de los educadores y estudiantes, ya sean jóvenes, adultos o adultos mayores y las características de los espacios sociales donde se desarrollan las experiencias.

Siguiendo el planteo de Elena Achilli (2001) diferenciamos las nociones de práctica docente y práctica pedagógica. Entendemos que la práctica docente "es una práctica desarrollada por sujetos cuyo campo identitario se construye alrededor de los procesos fundantes del quehacer educativo como son los procesos de enseñanza y de aprendizaje" (Achilli, 2001, p. 23). Por su parte, la práctica pedagógica es aquella que

se despliega en el contexto del aula caracterizada por la relación docente, alumno y conocimientos (...) La práctica docente, amén de constituirse desde la práctica pedagógica, la trasciende al implicar, además, un conjunto de actividades, interacciones, relaciones que configuran el campo laboral del sujeto maestro o profesor en determinadas condiciones institucionales y sociohistóricas (...) La práctica docente puede implicar actividades que van desde las 'planificaciones' del trabajo áulico a las actividades de asistencias alimentarias, de salud, legales, de colaboración con documentación de los alumnos u otras. (Achilli, 2001, p. 23) 
María Rosa Brumat/Diego Agustín Moreiras Prácticas de enseñanza en la modalidad domiciliaria:

Cruces con la educación rural y el uso de TIC Revista Xihmai XVI (31), 39-74, enero-junio 2021

En el marco de este artículo asumimos la práctica pedagógica como sinónimo de prácticas de enseñanza y nos detenemos particularmente en ellas; dejamos de lado otros aspectos, por lo tanto, que constituyen las prácticas docentes de Ana: tareas de coordinación y articulación con las/os docentes de las escuelas de origen de las/os estudiantes que se encuentran transitando su educación en la Modalidad Domiciliaria y Hospitalaria; articulación con otros profesionales, médicos, por ejemplo; coordinación con las autoridades; organización semana a semana de sus jornadas laborales diarias, por mencionar sólo algunas.

Los docentes hospitalarios y domiciliarios desarrollan sus tareas en condiciones muy distintas a las habituales de una escuela común; su práctica está orientada a brindar una atención integral que apunta a garantizar el derecho a la educación de niños y jóvenes en situación de enfermedad.

Algunos autores (Serradas, 2015; León, 2015) puntualizan funciones específicas de los docentes de esta modalidad como trabajo articulado con los equipos médicos y sanitarios que asisten a los niños; búsqueda de información sobre la situación de enfermedad de sus alumnos; colaboración con los padres en los procesos de aprendizaje; articulación y apoyo con las escuelas sedes; elaboración y adaptación de materiales curriculares según las necesidades educativas; búsqueda de asesoría en dificultades específicas del aprendizaje; elaboración de un programa de vuelta a la escuela; inclusión social y escolar.

Por otra parte, el docente debe conocer la enfermedad de sus alumnos y su trascendencia para poder ayudar a comprenderla y apoyar a su recuperación dentro de la complejidad que implica al niño y su familia (Ortiz, 2000).

Para Gándara y Junquera (2006), la función principal de este profesional sería establecer los canales de comunicación adecuados, entre el medio escolar y el hospitalario, que permitan ir adaptando la actividad escolar a la situación física y emocional del estudiante en cada fase de la enfermedad. De esta manera, se trata de evitar la ruptura con la escuela y se sientan las bases y condiciones para el momento de su retorno.

Requena (2011) analiza las prácticas educativas de docentes con niños internados en una escuela hospitalaria y plantea que la presencia de la maestra permite obtener un punto de referencia importante

Xihmai 48 
María Rosa Brumat/Diego Agustín Moreiras Prácticas de enseñanza en la modalidad domiciliaria:

Cruces con la educación rural y el uso de TIC Revista Xihmai XVI (31), 39-74, enero-junio 2021

para constituir el lugar, simbólico, de lo escolar (...) A diferencia de lo que ocurre en la escuela "normal", en la que todos los niños se ponen a trabajar bajo determinada consigna, en la escuela hospitalaria, por lo general, el trabajo es de a uno por vez y la consigna "varía" según el niño, no sólo por su estado general de salud sino también por el grado de escolarización que tiene y los contenidos que viene trabajando en la "escuela de origen". (p. 10)

Algunos autores plantean que el uso pedagógico de las TIC como instrumento de enseñanza y aprendizaje de docentes hospitalarios y domiciliarios ayuda a mejorar el estado de ánimo de los niños (Peirats et al., 2017).

Algunos estudios de investigación señalan que existen otros factores importantes como son la participación de la institución escolar y el beneficio reportado al grupo-clase donde se escolariza el niño o joven hospitalizado. Ellis et al. (2013) plantean que el programa aplicado ayuda a establecer una estrecha relación con la escuela y genera un gran beneficio en la reincorporación a la misma, así como el éxito social y académico.

Como ya hemos mencionado antes, las prácticas pedagógicas de Ana en el momento en que la entrevistamos se encuentran en un cruce con algunas particularidades de la modalidad rural, debido a que las/os estudiantes con quienes trabaja en ese momento pertenecen a escuelas rurales. Algunos trabajos de investigación en torno a la educación rural resultan útiles a nuestros fines, toda vez que ponen de relevancia la necesidad de prestar atención a la cotidianeidad de las prácticas docentes así como sus vínculos con el medio social en el que tienen lugar (Díaz Orozco \& Gallegos Valdés, 1997; Tovar, 1989; Ezpeleta, 1992; Ezpeleta \& Weiss, 1996).

En Argentina los desarrollos académicos sobre la formación y práctica de docentes rurales generalmente centran la atención en las condiciones de su trabajo y de intervención pedagógica (véanse, por ejemplo, Jacinto, 1988; Ezpeleta, 1991; Thisted, 1997). Estas investigaciones aportan a la comprensión de las prácticas docentes en espacios rurales y en contextos de enseñanza en plurigrado, a la vez que contribuyen a pensar las características propias de cada país y en continuidades y discontinuidades en procesos regionales latinoamericanos. En sus ideas más generales estos trabajos nos ofrecen una perspectiva desde la cual abordar las prácticas docentes y, en particular, de enseñanza de la docente entrevistada. 
María Rosa Brumat/Diego Agustín Moreiras Prácticas de enseñanza en la modalidad domiciliaria:

Cruces con la educación rural y el uso de TIC Revista Xihmai XVI (31), 39-74, enero-junio 2021

Nos interesa indagar en las prácticas docentes de Ana toda vez que consideramos que podemos recuperar de ellas aspectos que pueden ser conceptualizados como "buenas prácticas" en educación domiciliaria (Molina et al., 2019), sobre todo en términos de la propuesta metodológica que construye la docente, incorporando TIC, para favorecer la continuidad de la trayectoria pedagógica de las/os estudiantes con quienes trabaja, "incluyendo estrategias y acciones concretas de reinserción social" y escolar (Molina et al., 2019, p. 15). Por ese motivo, a continuación, resulta necesario recuperar algunas ideas en torno al trabajo docente con dispositivos y tecnologías digitales.

\subsection{Prácticas docentes con dispositivos y tecnologías digitales}

[...] las Tecnologías de la Información y la Comunicación (TIC) han cambiado de forma radical la vida cotidiana entre los distintos contextos educativos, ya que permiten mejorar la comunicación y coordinación entre centros educativos, familia, hospital; además de disminuir el aislamiento del menor, al que ahora se le ofrecen nuevas formas de aprender y relacionarse. (Granados \& Peirats, 2016, p. 403)

En los últimos años las investigaciones sobre la modalidad hospitalaria y domiciliaria se han multiplicado y resulta posible encontrar múltiples estudios y publicaciones en nuestro idioma que así lo demuestran. En muchos casos, se trata de informes de investigaciones realizadas a gran escala, con metodologías que incluyen estrategias cuantitativas, cuantioso financiamiento oficial y que contemplan diferentes actores de la modalidad: docentes, estudiantes, familiares, personal de salud, entre otros (Palomares et al., 2016; Granados \& Peirats, 2016; Molina et al., 2019, sólo por mencionar algunas). Es frecuente encontrar en ellas referencias específicas al trabajo con TIC. Algunas, además, tienen como objetivo especialmente la construcción de propuestas y entornos para el trabajo con TIC en la modalidad (por ejemplo, Serrano \& Prendes, 2014).

De modo general, estos estudios acuerdan que las TIC favorecen las prácticas docentes y de enseñanza en la modalidad no sólo porque son una herramienta a través de la cual, como ocurre en otras modalidades, generan propuestas para el trabajo de las/os estudiantes con los contenidos y aprendizajes relevantes, sino porque permiten mitigar los efectos que la hospitalización y/o la permanencia en el domicilio tienen para ellas/os:

Xihmai 50 
María Rosa Brumat/Diego Agustín Moreiras Prácticas de enseñanza en la modalidad domiciliaria:

Cruces con la educación rural y el uso de TIC Revista Xihmai XVI (31), 39-74, enero-junio 2021

Estas tecnologías pueden permitir el acceso tanto a contenidos de ocio como educativos, además de proporcionar la posibilidad de mantener un contacto diario con la familia, los amigos y el centro escolar. De esta manera es posible atenuar la sensación de separación y aislamiento que sufren respecto del entorno habitual. De otro lado puede verse favorecido el desarrollo afectivo y social del niño, impulsando la expresión y la comunicación del alumnado hospitalizado, siendo además una excelente oportunidad para desarrollar destrezas en el uso técnico de estos medios. Finalmente, hay que destacar las posibilidades de los avances en la coordinación entre el centro de referencia y el aula hospitalaria. (Serrano \& Prendes, 2015, p. 189)

Nisselle, (2012) considera fundamental proporcionar netbooks en los hospitales a niños escolarizados y hospitalizados para contribuir a un “ambiente normalizado y a una conexión con el mundo 'exterior' que proporciona la oportunidad de comprometerse con el aprendizaje de este alumnado" (p. 17). Hopkins, (2013) (citado en Peirats et al., 2017, p.71) apoya esto afirmando que un aprendizaje personalizado ayuda a aplicar estrategias de apoyo más adecuadas y evitar el retroceso académico de los niños. Según Pivec, (2007) (citado en Peirats et al., 2017) el aprendizaje mediante las TIC y los juegos digitales incrementan la motivación del alumno y facilitan la comunicación e interacción entre los mismos.

Algunos autores analizan las conexiones con el mundo exterior a través de las TIC y plantean el uso de los laptops como tecnología por excelencia (Nisselle et al., 2011) y el uso de la telefonía móvil con familiares, señalando que esto ha alcanzado una mayor conectividad y conciencia de cercanía por la facilidad de su uso (Heidari et al., 2015). En ambos estudios se afirma que la simple presencia de dispositivos móviles crea un ambiente normalizado y de seguridad tanto en los familiares como en los propios pacientes.

La variedad de funciones que se atribuyen a estas tecnologías en el ámbito de la modalidad resultan evidentes. Serrano y Prendes sistematizan esta variedad de posibilidades en torno a tres aspectos que las engloban: académicoformativo, psicosocial y como herramienta de comunicación (2015, p. 188).

Más allá de las dimensiones compartidas que venimos reseñando, algunos estudios presentan experiencias específicas. Por ejemplo, en un artículo de Serrano y Prendes (2014) dan cuenta de un entorno digital diseñado por ellos a partir de un trabajo inicial de relevamiento de información, que integra 
María Rosa Brumat/Diego Agustín Moreiras Prácticas de enseñanza en la modalidad domiciliaria:

Cruces con la educación rural y el uso de TIC Revista Xihmai XVI (31), 39-74, enero-junio 2021

entornos de la web 2.0 y de recursos digitales educativos en red, denominado ALTER. Esta propuesta supone la programación de un espacio web que funciona como banco de recursos y propuestas para la modalidad, iniciado por un equipo de especialistas que, además, se propone que pueda ser continuado por las/os docentes de la modalidad. No obstante, señalan que experiencias similares fracasan por falta de mantenimiento, debido a los costos que involucran (Serrano \& Prendes, 2014, p. 32). Lo mismo es señalado en otros estudios similares (Granados \& Peirats, 2016, p. 397).

Nos detenemos en esta propuesta debido a que involucra a especialistas en su desarrollo y mantiene a las/os docentes en un rol secundario, como informantes clave y con cierta ajenidad en el desarrollo. Esto supone potenciar aspectos tecnológicos, en detrimento de otros que puedan tener a las/os docentes como actores centrales. De modo similar es planteado por Serrano y Prendes: "Otra de las conclusiones obtenidas es la tendencia casi absoluta a evaluar las experiencias teniendo más en cuenta las tecnologías que las metodologías" (2015, p. 190) (cursivas nuestras).

Así, en este artículo en particular y en el proyecto de investigación que le da origen, nos proponemos realizar el movimiento opuesto: prestar atención de manera especial a las propuestas metodológicas de las/os docentes para el trabajo en la Modalidad Domiciliaria y Hospitalaria:

Así, Nisselle et al. (2012) consideran que el verdadero potencial del uso de los portátiles para contactar con la escuela de manera regular no ha sido desarrollado (...) en algunos estudios se comprobó que pocos profesores fueron capaces de utilizar con eficacia los recursos TIC para comunicarse con los estudiantes hospitalizados y para proporcionar interacciones de aprendizaje en red con el resto de la clase. (Serrano \& Prendes, 2015, p. 190-191)

El verdadero potencial de los portátiles y el uso de las TIC para promover procesos de comunicación son aspectos escasamente abordados en los estudios relevados y que resultan importantes en el nuestro. Esta preocupación va en línea con estudios de experiencias pedagógicas que ponen el acento en las prácticas docentes para la enseñanza con

dispositivos móviles y tabletas y desarrollando el Mobile Learning, [que] han roto las barreras del espacio y tiempo que tanto afectan al alumnado convaleciente, mejorando la gestión de la información, la consulta de contenidos digitales y la comunicación e interacción social de dicho alumnado (Granados \& Peirats, 2016, p. 399)

Xihmai 52 
María Rosa Brumat/Diego Agustín Moreiras Prácticas de enseñanza en la modalidad domiciliaria:

Cruces con la educación rural y el uso de TIC Revista Xihmai XVI (31), 39-74, enero-junio 2021

Se señala además la necesidad de pensar que las TIC ingresen en las propuestas de enseñanza a partir de trabajos en línea, ubicuos y en entornos colaborativos, que apuntan a "la modificación de los modelos educativos para incluir la educación online, a través de un aprendizaje basado en métodos colaborativos, empleando las redes y las comunicaciones" (Granados \& Peirats, 2016, p. 387).

Las prácticas de Ana que hemos relevado tienen la particularidad, además, que son llevadas adelante en un escenario de ruralidad, ya que se trata de servicios domiciliarios con estudiantes matriculados en escuelas rurales. Esto suma ciertas particularidades a lo que hemos planteado hasta aquí en torno a la modalidad hospitalaria.

Diversos estudios señalan las particularidades y limitaciones que tienen las propuestas de incorporación de TIC en escuelas rurales: desde aspectos vinculados con el acceso a los dispositivos tecnológicos (sean computadores de escritorio, personales tipo notebook o teléfonos celulares "inteligentes"), la posibilidad de contar con conectividad de manera continua y estable y los usos pedagógico didácticos que las y los docentes proponen (Molina \& Mesa, 2018; Zattera, 2017; González, 2017; Lescano, 2017; Sánchez \& Navarro, 2015; Tamargo \& Carniglia, 2020, entre otros).

No podemos detenernos aquí en la profundización de estos aspectos en relación al contexto en el que desarrollamos la investigación ya que no corresponde al foco de interés de este escrito. No obstante, sí podemos señalar que las escuelas rurales en las que son alumnos quienes trabajan con Ana desde sus hogares quedan relativamente al margen debido a que Ana debe resolver sus prácticas docentes en contextos domiciliarios (y no dentro de los edificios escolares, que poseen desiguales características de infraestructura vinculadas a TIC).

Así, podemos verificar las hipótesis de Cintia Tamargo y Edgardo Carniglia (2020), quienes afirman que las docentes rurales por ellos investigadas, "incorporan de modo periférico y desigual las computadoras, las redes digitales y la telefonía celular en las dimensiones pedagógico-didáctica, organizacional, administrativa y comunitaria del trabajo docente" (p. 420). En este sentido Ana es, de acuerdo a sus palabras, entusiasta e inquieta cuando de inclusión de TIC en prácticas educativas se trata, como mostraremos más adelante.

Por lo tanto, para el trabajo pedagógico que presentamos aquí lo relevante es la situación de cada familia y, como se verá más adelante, Ana debe aportar 
María Rosa Brumat/Diego Agustín Moreiras Prácticas de enseñanza en la modalidad domiciliaria:

Cruces con la educación rural y el uso de TIC Revista Xihmai XVI (31), 39-74, enero-junio 2021

todos los elementos de trabajo para garantizar el proceso educativo, debido a que los hogares de los estudiantes se encuentran en zonas sin cobertura de internet y no poseen dispositivos tecnológicos propios; así, Ana trabaja desde su propio teléfono celular, conectado a través de datos móviles pagados por ella misma.

Luego del recorrido anterior estamos en condiciones de señalar algunas dimensiones que resultan relevantes en nuestro abordaje:

a. indagar en las prácticas de enseñanza llevadas adelante por la docente de la modalidad (que incorporan sistemas de mensajería instantánea y entornos colaborativos para el trabajo con correos electrónicos, documentos de presentaciones y de otro tipo);

b. dar cuenta de los repositorios que utiliza la docente, cómo los selecciona y de qué manera los incorpora en su propuesta. Esto resulta importante, ya que Pintó (2011) afirma "que los docentes de aulas hospitalarias necesitan disponer de un amplio y organizado repositorio de recursos con criterios pedagógicos para poder seleccionarlos según las necesidades de cada situación" (Granados \& Peirats, 2016, p. 395).

c. relevar las estrategias que la docente propone para el trabajo con tecnologías y dispositivos móviles cuando las familias de las/os estudiantes con quienes trabaja no cuentan con el acceso a estos o con conexiones estables a internet.

Para dar cuenta de estos tres aspectos recuperamos el modelo de análisis de prácticas de inclusión de tecnologías en propuestas de enseñanza de Peter Twining (2002) denominado Modelo de Prácticas con Computadoras (CPF, por sus siglas en inglés). De los tres componentes que propone el autor (Cantidad, Foco y Modo), nos interesan sobre todo los dos últimos, en términos de los objetivos propuestos para el uso de los dispositivos y el impacto de este uso en el curriculum (en un sentido amplio de esta noción, como lo afirma Twining, 2002, p. 101), respectivamente ${ }^{4}$. Nos interesa la propuesta del autor como un modelo sistemático, de amplia circulación sobre

\footnotetext{
${ }^{4}$ Si bien el autor no se detiene específicamente en la definición de computadora, nos parece posible, en función de los desarrollos vinculados a microinformática y telecomunicaciones, asumir que los teléfonos móviles denominados smartphones o teléfonos inteligentes pueden ser considerados computadoras. Por lo tanto, incorporamos los desarrollos del modelo de Twining (2002) con esta salvedad.
}

Xihmai 54 
María Rosa Brumat/Diego Agustín Moreiras Prácticas de enseñanza en la modalidad domiciliaria:

Cruces con la educación rural y el uso de TIC Revista Xihmai XVI (31), 39-74, enero-junio 2021

todo en el mundo angloparlante, que permite acercarse a prácticas con TIC en educación desde una perspectiva cualitativa y de corte etnográfica como la nuestra (más allá de los usos cuantitativos que se han hecho de este modelo con finalidades de evaluación de políticas públicas de incorporación de TIC en propuestas educativas) ${ }^{5}$.

\section{Marco metodológico}

El proyecto de investigación en el cual este artículo se inscribe se propone realizar un estudio socioantropológico, de corte etnográfico. Recupera un enfoque relacional, propio de la antropología, que busca aproximarse a la cotidianeidad social de los procesos estudiados sin perder de vista la interrelación dialéctica de esta con los procesos estructurales y sociohistóricos más generales en los que dicha cotidianeidad se inscribe (Achilli, 2009).

La relación entre el Estado y los sujetos (Ministerio de Educación, docentes, estudiantes y familias, por ejemplo) adquiere contenidos singulares e históricos en su vida cotidiana, al tiempo que operan "múltiples mediaciones" que no pueden ser definidas a priori, y es en ese campo de mediaciones donde se juegan los contenidos y modalidades concretas que asumen las diferentes políticas y programas estatales. La posibilidad de "documentar" cómo funcionan estas dinámicas nos ha llevado a preguntarnos por el accionar de los sujetos en la medida en que estos aceptan, rechazan, redefinen y transforman las prescripciones (Montesinos et al., 2010).

La perspectiva teórica desde la cual construimos nuestro objeto de investigación supone el esfuerzo de contextualización múltiple y la necesidad de combinar diferentes procedimientos que permitan abordar la complejidad de casos seleccionados. En realidad, más que estudio de casos se plantea un "estudio en caso" (Geertz, 1987) que exprese la direccionalidad histórica que está en juego en los procesos y relaciones investigadas.

\footnotetext{
${ }^{5}$ El autor afirma que "This ability [del modelo] to work across phases/sectors is a design feature of the $\mathrm{CPF}$ and is based on the assumption that whilst the terminology and organisation of learning may vary across contexts, the underlying dimensions of educational practices that are encapsulated within the CPF all still apply (Twining, 2002, p. 101). Así, aún cuando la organización del aprendizaje de las/os estudiantes en la modalidad sea diferente a la de otras modalidades del sistema, el modelo ofrece aún la posibilidad de abordarla con fines de conocimiento.
} 
En este artículo en particular, esto supone comprender las significaciones que le otorga Ana a su trabajo docente en la modalidad. Una de las claves para comprender "las decisiones educativas (no necesariamente racionales 0 conscientes) que los sujetos toman en relación con la educación, tienen que ver con sus "trayectorias sociales", no solo educativas, sino las relativas a la organización familiar, las laborales, migratorias y de participación social" (Cragnolino 2006, citada en Montesinos et al., 2010). Por lo tanto, nuestra estrategia metodológica fundamental ha consistido en entrevistas con la docente, a partir de las cuales hemos reconstruido sus prácticas docentes y los sentidos asociados a ellas por parte de Ana. Por las particularidades del trabajo en la modalidad nos hemos limitado a la realización de entrevistas con la docente y no hemos realizado observaciones participantes de sus prácticas. Sin duda, esto sería una línea interesante para abrir indagaciones a futuro.

A continuación, presentamos algunos de los resultados obtenidos del análisis de estas entrevistas, en función de dos coordenadas: la modalidad domiciliaria y hospitalaria en el cruce con otras modalidades (la educación rural en nuestro caso) y las características de las prácticas docentes con TIC que lleva adelante Ana.

\section{Resultados parciales con discusión}

\section{1.a Prácticas docentes de Ana, maestra domiciliaria}

Nos interesa compartir el caso de Ana, una docente de nivel primario que se desempeña en la modalidad domiciliaria y hospitalaria que trabaja con alumnos matriculados en escuelas de contextos rurales.

Ana trabaja, en el momento de la entrevista, con alumnos en cinco domicilios, aunque el número varía incluso de semana a semana. Ella organiza su trabajo y sus visitas con los padres de sus alumnos previamente con una semana de antelación debido a que los niños se encuentran en tratamientos médicos y pueden no encontrarse bien para recibir clases, y/o suelen asistir a controles. Este trabajo de coordinación con los padres consiste en que puedan acomodar la rutina de su hogar y la vida cotidiana de la familia para que los niños puedan tomar las clases en el día habitual que corresponde. Lo único que puede suspender o interrumpir las clases son cuestiones médicas de sus tratamientos. Todo esto es parte de los acuerdos para el inicio del servicio domiciliario,

Xihmai 56 
María Rosa Brumat/Diego Agustín Moreiras Prácticas de enseñanza en la modalidad domiciliaria:

Cruces con la educación rural y el uso de TIC Revista Xihmai XVI (31), 39-74, enero-junio 2021

firmado en un acta con los padres de los alumnos donde se establecen los horarios, posibilidades de cambio, condiciones del trabajo.

Generalmente trabaja con dos niños por día, en el turno matutino que es el que establece su cargo, pero siempre atendiendo a las situaciones particulares y a las condiciones en que se encuentre cada alumno:

E: Eso te iba a preguntar... ¿Cuántos alumnos tenés en este momento?

A: Cinco. En este momento. Hubo oportunidades que tuve 10. Entonces, ¿qué hacía? Divido. Hago semana A y semana B. Si esta semana te doy dos veces a vos, la próxima te voy a dar una. El hecho es que todos tengan la misma cantidad y su momento de educación. Y cuando tenía diez, a algunos los veía una sola vez y a otros dos veces.

E: Y ahora que tenés cinco, ¿cuánto los ves?

A: Dos niños por día. Eso me alcanza. Depende. Ahora, si me toca una distancia acá en Chilecito, que es muy raro que me toque en el mismo radio, te puedo llegar a hacer tres. Porque estoy una hora cuarenta... También depende del niño: si el niño está medicado y no necesita tanto momento, estar con tanta concentración, entonces bueno, ya es menos tiempo. A veces me toca que los estoy evaluando y necesitan más tiempo para resolver una prueba y les doy la opción: si quieren terminar o prefieren que vuelva después. En esos casos, cuando ya se cumplió el horario, les doy la alternativa. (Ana, comunicación personal, 11 de noviembre de 2019)

Ana articula y coordina con las maestras de sus alumnos, el trabajo pedagógico que ella desarrolla con cada uno. A la vez que va informando de su situación, sus avances, y la posibilidad de que se integre nuevamente a la escolaridad en la escuela:

A: Articular con las maestras los contenidos, los modos de evaluar, los modos de enseñar, las actividades. Eso sería con la escuela. También, a veces, informar si se dio de baja un servicio, si se acabó un certificado médico. Yo cuando se termina un certificado médico tengo que hacer un informe. Entonces, agilizo el trámite y llamo a la maestra y le digo: Mire, hoy termina el certificado médico, pronto se le entrega un informe. Cuando se termina el certificado quiere decir que ese alumno vuelve a la escuela. (Ana, comunicación personal, 11 de noviembre de 2019)

Estas tareas que ella describe conforman una amplia gama de actores e instituciones con quienes la maestra genera acuerdo, produce y entrega documentos con la finalidad de garantizar las trayectorias escolares de los estudiantes con quienes está trabajando cada semana. En su caso, lo específico de la modalidad domiciliaria se cruza con lo rural y sus determinaciones. 
María Rosa Brumat/Diego Agustín Moreiras Prácticas de enseñanza en la modalidad domiciliaria:

Cruces con la educación rural y el uso de TIC Revista Xihmai XVI (31), 39-74, enero-junio 2021

\section{1.b En el cruce de modalidades domiciliaria y rural}

Si bien Ana es una maestra que pertenece a la modalidad de Educación Domiciliaria y Hospitalaria, sus alumnos viven en zona rurales y son alumnos de escuelas rurales. Institucionalmente, se encuentran inscritos en una escuela rural y formalmente son alumnos de esa institución. Ana brinda un servicio domiciliario para garantizar su escolaridad obligatoria mientras se encuentren en situación de enfermedad en sus domicilios.

A su vez, ella debe movilizarse y llegar a cada uno de los domicilios de sus alumnos y sus familias en distintas zonas rurales con su auto:

A: Mi directora sería la Supervisora, directamente. Yo dependo directamente de la Supervisora. Así que ella tiene conocimiento de... Incluso ella... Me ha ocurrido una vez que fui para una finca que queda en Nonogasta, muy al fondo. No sé cuántos kilómetros. La finca de Bellia. Se me pinchó un neumático y no sabía cambiarlo. Hacía por lo menos una hora y veinte que estaba ahí parada y no sabía cambiarlo. Entonces, detrás de esa situación, le sugerí a la Super que ella trate de registrarme por ubicación. A través del teléfono. Que ella sepa dónde yo estoy. Me gusta porque me siento también contenida, en cierta forma. Porque... por una cuestión de seguridad. Otra vez me tocó un allanamiento. Entonces. ¿Qué hice? Desde ahí, yo con ella hablé previamente... Yo también, mi horario el viernes también se lo mando a ella. Qué día voy a estar, donde voy a estar. Y entonces eso también la ayuda a ella para buscarme en el mapa para saber dónde estoy. O sea, más allá de un control, porque no me hace falta que me controlen porque yo voy a ir a trabajar, o sea, me gusta lo que hago, me apasiona y no es por una cuestión de control, de si voy a ir a trabajar o no, sino que es una cuestión de seguridad. (Ana, comunicación personal, 11 de noviembre de 2019)

Lo que relata Ana aquí da cuenta de la complejidad y algunas particularidades de su tarea docente en contextos rurales. Esta característica nos muestra que en la realidad de la práctica cotidiana se produce un "cruce de modalidades" entre domiciliaria y rural, que procura garantizar el acceso y el derecho a la educación de estos alumnos en situación de enfermedad, particularmente en zonas rurales:

E: ¿Alguno de los estudiantes con los que estás trabajando ahora es de una escuela rural?

A: Sí. En este momento, los cinco alumnos son de escuela rural. Sí.

E: Ah, mira. Si vos tuvieras que pensar si hay alguna diferencia entre los alumnos con los que vos trabajás que son de escuelas urbanas, digamos, y los alumnos que son de escuela rural, ¿hay alguna diferencia para vos, en tu trabajo?

Xihmai 58 
María Rosa Brumat/Diego Agustín Moreiras Prácticas de enseñanza en la modalidad domiciliaria:

Cruces con la educación rural y el uso de TIC Revista Xihmai XVI (31), 39-74, enero-junio 2021

A: Yo digo que sí, en cuanto a las posibilidades, por ejemplo, de obtener las redes sociales. El poder estar conectados más tiempo. Un chico de acá de la ciudad tiene los $4 \mathrm{G}$ y todo eso y tiene más accesible. O tiene más plazas, tiene más oficinas que vos pasás y te conectás. En cambio un niño que vive a, cómo te voy a decir, a cuatro kilómetros de una escuela, no, no tiene ese alcance. Por eso es que yo facilito mi teléfono. Y las cuestiones económicas son muy diferentes. (Ana, comunicación personal, 11 de noviembre de 2019)

En la actualidad, vemos que existen otras realidades y relaciones que exceden este orden planteado institucional e históricamente. El reconocimiento de las modalidades educativas asume otras formas del enseñar y aprender. Esto nos invita a pensar las características que asume el dispositivo escolar en estas realidades y contextos. En el sentido en que lo plantea Terigi (2006):

El dispositivo escolar genera una instancia colectiva para el aprendizaje. Este carácter colectivo de la escuela puede entenderse mejor si se la compara con otros dispositivos instruccionales, como la enseñanza a cargo de institutrices o preceptores: en ella también encontramos un enseñante, pero su trabajo se realiza con pocos aprendices y es completamente aceptable que se realice con uno solo. (p. 196)

En el caso de la maestra domiciliaria que analizamos, el carácter colectivo simultáneo de la enseñanza se rompe para construir otra forma que no sigue el criterio de simultaneidad de la escuela tradicional pero que trata de mantener el carácter colectivo del aprendizaje al vincular de manera permanente al alumno en situación de enfermedad con su docente y sus compañeros de la escuela sede.

En este caso, las prácticas de la enseñanza desarrolladas por Ana, estarían dando cuenta de una invención del hacer (Terigi, 2006) en el que la docente resuelve y toma decisiones sobre la enseñanza según las particularidades de este contexto. Terigi plantea este concepto de invención del hacer para referirse a las decisiones que toman los docentes (especialmente, los maestros rurales) respecto al "agrupamiento de los alumnos, la secuenciación de los contenidos de enseñanza, el manejo del tiempo y los recursos y materiales, entre otros aspectos de la organización didáctica de la clase" (p. 202) y estas decisiones se toman siempre considerando los contextos didácticos específicos. Según la autora, esta invención se da sin haber tenido formación inicial en estos temas: todos los conocimientos que esta maestra reconoce en la actualidad han surgido de la experiencia que ella misma ha forjado desde su inicio como docente en la modalidad. En el caso de Ana, esto fue hace siete 
María Rosa Brumat/Diego Agustín Moreiras Prácticas de enseñanza en la modalidad domiciliaria:

Cruces con la educación rural y el uso de TIC Revista Xihmai XVI (31), 39-74, enero-junio 2021

años cuando en las ofertas de formación inicial y continua, eran infrecuentes espacios para las modalidades domiciliaria y hospitalaria; en la actualidad, ella misma da cuenta de la comodidad que tiene con sus tareas actuales y de las formas sistematizadas en que toma decisiones y construye sus propuestas de enseñanza. En este sentido, resulta central el lugar que tienen las TIC y la comodidad con la que Ana se maneja en entornos digitales.

\subsection{Uso de las TIC en la enseñanza: aula ampliada en el trabajo de esta maestra}

\section{2.a. Las prácticas de enseñanza de la docente}

Tradicionalmente, el proceso de enseñanza y aprendizaje se establece en la clase escolar, en el marco de un aula: un dispositivo escolar que consta de una arquitectura y una organización de un espacio y un tiempo dedicados a compartir los conocimientos.

Marta Souto describe a la clase escolar como:

El escenario donde se producen las prácticas pedagógicas" (...) "un ámbito delimitado por el aula en lo espacial y por el año lectivo en lo temporal. Es el ambiente donde los eventos, los sucesos transcurren. Pero la clase es más que ello, abarca los procesos y las relaciones que en ese ambiente se producen (...) es el lugar que sostiene lo pedagógico. Es en ella donde se organizan las relaciones con el saber, que se cumple la función de saber (...) y que se definen los lugares asimétricos en la relación [docente-alumno] (Souto, 1996, pp.136-137).

Desde que la educación a distancia existe, las coordenadas espaciales y temporales del aula se han visto flexibilizadas a partir de diferentes estrategias comunicacionales y didácticas (a partir del correo postal en sus inicios o del uso de medios masivos de comunicación, como la radio o la televisión, luego). Pero es recién con la llegada de las nuevas TIC, asociadas a la informática y al lenguaje digital, que comienzan a surgir conceptos "como 'aula aumentada' (Sagol, 2012), 'aprendizaje aumentado' (Reig, 2012), 'aprendizaje ubicuo' (Burbules, 2014) y hasta los más recientes 'entornos personales de aprendizaje' (Castañeda \& Adell, 2013)" (Martín, 2016), entre otros. Como ya adelantamos, en este escrito nos concentramos en la primera de estas nociones, debido a que es la que utiliza la propia docente. Otras nociones pueden ser relevantes para el análisis de las prácticas de Ana, pero aquí deseamos mostrar de qué manera

Xihmai 60 
María Rosa Brumat/Diego Agustín Moreiras Prácticas de enseñanza en la modalidad domiciliaria:

Cruces con la educación rural y el uso de TIC Revista Xihmai XVI (31), 39-74, enero-junio 2021

la que ella utiliza es en realidad superada y si cabe, mejorada, por sus prácticas, aunque quizá esto no resulte evidente para ella.

Cecilia Sagol propone el concepto de aula aumentada y socializa la noción sobre todo en entornos de formación docente. La característica central que ella define para esta noción tiene que ver con "la combinación de elementos del mundo real con elementos virtuales" (Sagol, 2013), es decir, la articulación de elementos de la clase presencial con aquellos propios de entornos digitales. Se trata, en gran medida, de que lo virtual complemente lo presencial a partir del uso de blogs, carpetas compartidas, aulas en plataformas virtuales, grupos en redes sociales (Sagol, 2013). Un aspecto central es "la circulación de contenidos digitales (con sus múltiples opciones de convergencia y transformación)" (Martín, 2016) que implican que,

cada docente dispone de un aula presencial, un espacio físico de fuerte impronta interpersonal, fijo en el tiempo y en el espacio, y un espacio virtual donde se genera otro tipo de comunicación asincrónica, mediada por tecnologías, fuera del horario de clase, más horizontal, etc. Lo mejor de los dos mundos, sin duda. (Sagol, 2013).

Queda claro entonces que lo central de esta noción está dado por la posibilidad de que las/os estudiantes puedan conectarse a entornos virtuales para interactuar por sí mismas/os en esos espacios con los contenidos y materiales preparados por el/la docente y esta conexión puede desarrollarse antes, durante o después del encuentro presencial sincrónico en el aula de la escuela.

Nos interesa esta noción porque Ana la utiliza asiduamente para describir sus propuestas de enseñanza. Ella utiliza el concepto de "aula ampliada" para dar cuenta del trabajo que realiza, de un modo propio, que reformula y expande esa noción. Ella alude al concepto de aula ampliada cuando hace referencia a una "ampliación de los límites del aula tradicional de trabajo con los alumnos":

E: Quería que me contaras cómo es este trabajo desde el aula ampliada que realizás. Ana: Aula ampliada es un proyecto, debido a esta situación de los chicos que quedan separados del contexto educativo. Ampliar los contenidos, los conocimientos a través de las redes sociales. Se usa el espacio virtual para transmitir lo pedagógico. Eso es. A eso se refiere el aula ampliada. O sea, a mí me interesa un artículo de Cecilia Sagol y con base a eso me interesó. De hecho, yo siempre trabajé pero mi proyecto lo fundamenté en cuanto a eso: usar las redes sociales para hacer nexo entre lo que es lo afectivo y las estrategias pedagógicas para poder llevar un proyecto pedagógico hacia el domicilio. Para que tenga una 
María Rosa Brumat/Diego Agustín Moreiras Prácticas de enseñanza en la modalidad domiciliaria:

Cruces con la educación rural y el uso de TIC Revista Xihmai XVI (31), 39-74, enero-junio 2021

participación más directa del alumno con su grupo de aula. (Ana, comunicación personal, 11 de noviembre de 2019) (cursivas nuestras)

Ana: Y, ellos también, si no entienden una actividad, que me manden audios. Ellos me mandan: Seño, ¿esto era? ¿hasta dónde era? Ehhh, así. También me comunico con los estudiantes cuando no estoy. Por eso yo digo que es un aula ampliada. Continuamos la educación. No es sólo en ese horario que uno está, sino que la tecnología es ahora, y más tarde, mañana. Aunque yo no esté como docente. Ellos tienen que seguir. A través de eso, del aula ampliada. (Ana, comunicación personal, 11 de noviembre de 2019) (cursivas nuestras)

En el primer fragmento, Ana menciona a Sagol y da cuenta que conoce su propuesta: afirma que utiliza "espacios virtuales para transmitir lo pedagógico" y esto se encuadra de manera directa en la propuesta de la autora. En el segundo, queda claro, además, que hay un trabajo fuera de los momentos en los que Ana visita a estas/os estudiantes en el domicilio de cada una/o: la posibilidad de acceder a Ana a través de WhatsApp permite que sus estudiantes la contacten cuando surge alguna duda. No obstante, en el primer fragmento agrega, además, que le interesa esta noción para "hacer nexo" entre lo afectivo y lo pedagógico: esto constituye un primer aporte a esa noción realizado por la propia Ana. El aula ampliada supone entonces, para ella, la posibilidad de abordar también la dimensión afectiva de las/os estudiantes con quienes trabaja.

Encontramos, además, un segundo aspecto que para ella es importante en relación con esta noción:

A: Yo puedo impartirles los conocimientos, ¿sí? Pero para todo el conocimiento social, de su socialización, yo uso las redes. Por ejemplo, que hay actos. Tiene otra maestra que es de artística, otra que es de música. O sea, todo lo que se vivencia dentro de una escuela, uno lo puede hacer por medio de las redes. En este caso.

E: ¿Cómo es? ¿Él se conecta con sus maestras y con sus compañeros?

A: Sí, lo hago desde mi celular. Desde mi celular. (...) Y articulamos con la maestra de aula: Tal día yo voy a estar con tu alumno y me gustaría... se viene tal festividad en la escuela, tal proyecto. Bueno, me gustaría que sea partícipe. Que le preguntes a él, que está haciendo en la casa sobre eso y así.

E: ¿Quién lo escucha a él?

A: Sus compañeros y la docente, con una videollamada. Todos. $Y$ ahí interactúan los compañeros, lo saludan. O sea, sus compañeros lo conocen por videollamada. Porque hay compañeros que sí los ha tenido desde principio de año y hay otros que no, que han ingresado nuevos a la escuela. Entonces, todos sus compañeros están sabiendo de esta realidad de su compañero que no puede asistir, por medio de la 
María Rosa Brumat/Diego Agustín Moreiras Prácticas de enseñanza en la modalidad domiciliaria:

Cruces con la educación rural y el uso de TIC Revista Xihmai XVI (31), 39-74, enero-junio 2021

conectividad. (Ana, comunicación personal, 11 de noviembre de 2019) (cursivas nuestras)

Recuperamos un segundo aspecto que Ana suma a la noción de aula ampliada: se trata de la interacción sincrónica entre docente, estudiantes en la escuela y el/la estudiante en modalidad domiciliaria. El trabajo de Ana incluye, a su juicio, la sincronización de su presencia en el domicilio del / de la estudiante con la realización de eventos institucionales en la escuela de origen de cada una/o. Esto permite "que sea partícipe" y no sólo por asistir a ese evento en calidad de espectador, sino por responder preguntas que den cuenta de lo que ha aprendido en su hogar sobre la temática en cuestión.

Lo dice también de esta otra manera:

Antes era como que yo era una institución de educación domiciliaria y la escuela. Entonces, el chico se conectaba conmigo y pasaba a ser yo el contexto educativo. Pero en cambio, ahora sigue siendo la escuela y yo, porque a través de una videollamada que hago siguen conectados. En forma directa, con el grupo de pares. Sobre todo, ahí en la adolescencia. O por más que sea un primer grado, la conectividad nos conecta a los afectos. (Ana, comunicación personal, 11 de noviembre de 2019) (cursivas nuestras)

A modo de síntesis, podemos pensar que cada domicilio que visita se constituye en un tercer espacio (además del aula en la escuela y del entorno virtual): el domiciliario en sí. Este supone la copresencia entre docente y estudiante, admite el uso de entornos virtuales pero también la conexión con el espacio del aula escolar que quedó lejano: Ana se preocupa de sostener una vinculación frecuente con la escuela, la maestra y las/os compañeras/os de aula para que el estudiante domiciliario mantenga su sensación de pertenencia con la institución de la que se encuentra ausente. De esta manera, desde el punto de vista del estudiante domiciliario, en ese momento su aula es su hogar y se amplía tanto a entornos virtuales como a los espacios de la escuela a la que no puede asistir: por tal motivo, podríamos hablar de un aula domiciliaria doblemente ampliada.

Vemos entonces de qué manera Ana, desde su práctica, complementa esta noción de "aula ampliada": toma esta idea y la carga de contenido propio del trabajo en la modalidad. Y, esto amplía conceptualmente la noción planteada por Sagol, aunque se encuadra en un campo de sentidos posibles para esta noción. En la experiencia de esta maestra, se trata de ampliar el aula construida 
María Rosa Brumat/Diego Agustín Moreiras Prácticas de enseñanza en la modalidad domiciliaria:

Cruces con la educación rural y el uso de TIC Revista Xihmai XVI (31), 39-74, enero-junio 2021

en el domicilio a partir del uso de dispositivos y entornos digitales; a la vez, favorecer la dimensión emocional y afectiva que también es parte del proceso de aprendizaje de las/os estudiantes; y finalmente, supone la posibilidad de "hacer llegar" a las/os estudiantes domiciliarios sincrónicamente a la escuela, para "hacer nexo" y para que "sean partícipes" de lo que allí ocurre. Estos aspectos que Ana reconoce en su práctica, y articula en torno a la noción de "aula ampliada", guardan relación directa con lo recuperado antes desde Serrano y Prendes (2015), como dimensiones centrales de las prácticas de enseñanza en la modalidad: académico-formativo, psicosocial y como herramienta de comunicación, respectivamente.

A continuación, nos detenemos en una dimensión específica del trabajo de enseñanza: la búsqueda y selección de materiales y recursos.

\section{2.b. Los repositorios que utiliza la docente}

Decíamos antes, siguiendo a Pintó citado en Granados y Peirats (2016), que un aspecto central en el trabajo domiciliario está dado por la posibilidad de contar con repositorios de recursos, que permitan a las/os docentes de la modalidad encontrar materiales pertinentes para el trabajo pedagógico en cada caso.

Ana señala que las TIC le han permitido una transformación en sus prácticas, dado que ahora no depende sólo de los libros que tiene "que cargar" desde su casa hasta los domicilios de sus estudiantes para poder llevar adelante sus propuestas de enseñanza, sino que siempre tiene la posibilidad de recurrir a internet (Ana, comunicación personal, 11 de noviembre de 2019). En los casos en que las/os estudiantes pueden acceder por su cuenta a la red, ella hace una selección previa de materiales y les ofrece directamente los enlaces a sus estudiantes. "Veo qué links les voy a ofrecer para que ellos puedan leer, investigar y ver. Eso se ha usado mucho en mi trabajo" (Ana, comunicación personal, 11 de noviembre de 2019).

Además de la red en general, Ana reconoce algunos espacios específicos como valiosos para su trabajo:

Se usa mucho, sobre todo cuando los chicos se ven imposibilitados de poder escribir. ¿Me entendés? No pueden escribir, entonces, la mayoría de los temas los vemos a través de videos, documentales. Uso mucho el Canal Encuentro. A través de la facilidad del teléfono que lo buscás en la plataforma, por tema y todo. Mientras que esperarlo por tele, no sé en qué momento lo van a pasar. Ni en qué momento Xihmai 64 
María Rosa Brumat/Diego Agustín Moreiras Prácticas de enseñanza en la modalidad domiciliaria:

Cruces con la educación rural y el uso de TIC Revista Xihmai XVI (31), 39-74, enero-junio 2021

está el programa en la tele. Porque Canal Encuentro tiene todas sus cosas cargadas en internet. Entonces, es un gran facilitador. Me encanta el Canal Encuentro para estas cuestiones. Y mis niños los hago usar para investigar. (Ana, comunicación personal, 11 de noviembre de 2019)

La maestra expresa en este fragmento de manera clara la importancia que tiene para ella contar con esta plataforma del Canal Encuentro para la búsqueda de materiales didácticos, pero también para promover la búsqueda autónoma de sus propios estudiantes. No se trata solamente de reconocer las producciones del canal que pueden ser transmitidas masivamente a través de la televisión, sino también valorar que se encuentren a disposición y "a demanda del docente", en la plataforma que se ha creado desde el Ministerio de Educación 6 .

\section{2.c. Estrategias docentes para el trabajo con TIC y dispositivos móviles}

Si bien, este apartado es una parte de la propuesta de enseñanza de Ana desarrollada antes, hemos decidido darle un espacio especial porque creemos que hay especificidades para atender. En un apartado anterior, planteamos de qué modo se incorporaban las TIC en el trabajo de la maestra. Desde la propuesta de análisis de Twining (2002), podemos afirmar que aquellos usos se distribuían, de acuerdo al Foco, entre Herramientas de Aprendizaje y herramientas para Otros usos (vinculados a la dimensión afectiva / de socialización y a la comunicacional, de "hacer nexo" y "ser partícipes"). Deseamos ahora detenernos en el Foco en tanto Herramientas de Aprendizaje, para profundizar en los Modos en juego (ver Esquema 1).

\footnotetext{
${ }^{6}$ El Canal Encuentro comenzó su transmisión en el año 2007 y desde entonces sus producciones han sido alojadas en la plataforma en línea que el canal posee. Si bien, ha tenido algunas discontinuidades desde 2016 (momento en que abandona la órbita del Ministerio de Educación para pasar a depender de la Secretaría de Medios), la disponibilidad y gratuidad para el acceso a estos materiales ha sido una constante del Canal. Puede consultarse más información en: http://encuentro.gob.ar/acercade
} 
María Rosa Brumat/Diego Agustín Moreiras Prácticas de enseñanza en la modalidad domiciliaria:

Cruces con la educación rural y el uso de TIC Revista Xihmai XVI (31), 39-74, enero-junio 2021

\section{Esquema 1}

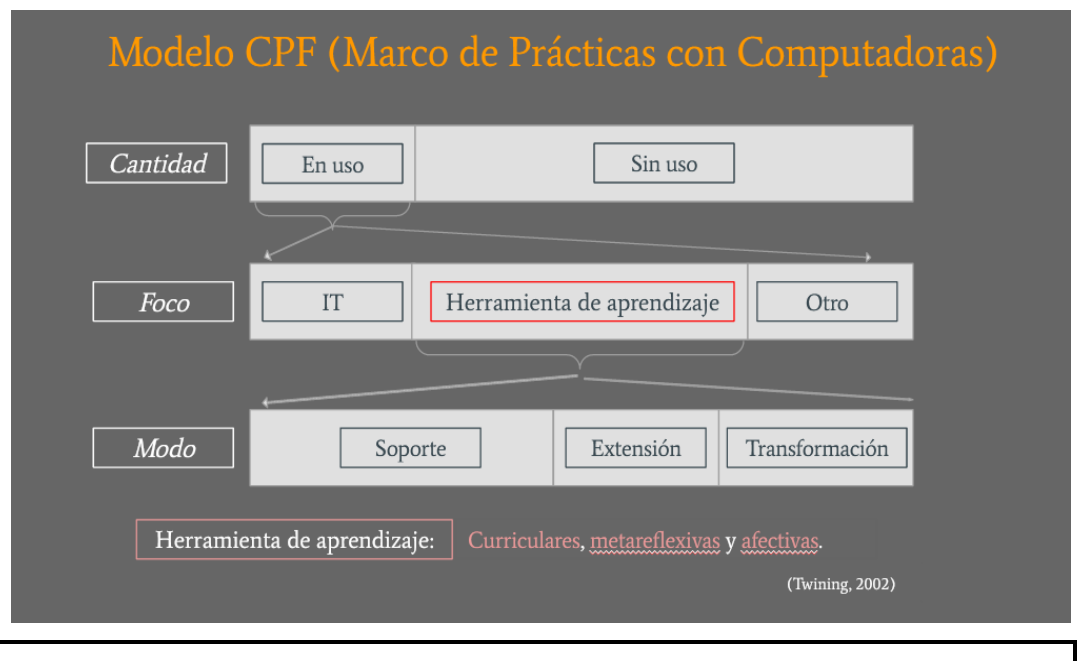

Elaboración propia a partir de un esquema del autor

(Twining, 2002, p. 106)

En el Modo Soporte los contenidos de aprendizaje son los mismos, así como el proceso (las formas en que se aprende) que en propuestas que no incluyen las TIC. El Modo Extensión implica que los contenidos y los procesos puedan ser diferentes, pero para llevarlos adelante no es necesario el trabajo con computadoras (Twining, 2002, p. 104). No podemos detenernos aquí extensamente en ejemplos extraídos de la entrevista para cada uno de estos modos. Baste con señalar que no todas las prácticas de enseñanza que lleva adelante Ana están mediadas por TIC: en el apartado anterior se ha ofrecido un ejemplo concreto de utilización de TIC para el trabajo con contenidos (recursos y materiales) del Canal Encuentro, que podrían abordarse simplemente a través de la televisión. Este sería un ejemplo de un uso en Modo Soporte. La mención que hacíamos del trabajo en entornos virtuales en la definición de aula ampliada que propone Sagol podrían ser pensados como ejemplos del Modo Extensión.

Xihmai 66 
María Rosa Brumat/Diego Agustín Moreiras Prácticas de enseñanza en la modalidad domiciliaria:

Cruces con la educación rural y el uso de TIC Revista Xihmai XVI (31), 39-74, enero-junio 2021

No obstante, quizá los aspectos más relevantes de acuerdo a las propias reflexiones de Ana se dan en el Modo Transformación, en el que los contenidos y los procesos son diferentes y las computadoras se vuelven herramientas excluyentes. En los siguientes fragmentos la entrevistada relata un proceso de trabajo con audios enviados desde su teléfono móvil por las/os estudiantes en sus domicilios a las docentes en las escuelas, y luego un trabajo de escritura que hace con estudiantes más grandes y el envío de actividades a través de una casilla de correo electrónico:

Y, bueno, sería pensar lo que van a hacer, fijarse que salga bien el audio, escucharlo, procesarlo. Después ver si lo hicieron bien. Esperar una respuesta, volver a leer. Es todo un procedimiento que lleva su tiempo. Más allá que a nosotros nos parezca que ellos lo hacen automáticamente. Yo pienso que más allá. Pero son pasos que no es así nomás, al turuleco. O sea, tienen que procesar para hacer esto. Es un aprendizaje. Es un aprendizaje. (Ana, comunicación personal, 11 de noviembre de 2019) (cursivas nuestras)

Es todo un proceso. Va a tener que leer igual. Hacer ese proceso. Buscarlo al docente, practicar. Después leer. "Bueno, escuchalo si está lindo el audio, si estás conforme, yo le digo, si estás conforme, si crees que has leído bien, bueno, mandaselo". O “Borralo, lo volvamos a hacer...". Son procesos.

E: Y este alumno, por ejemplo, dice "No me gustó” o "Sí me gustó”...

A: Sí. Se corrige. Porque al momento que va leyendo, si separa mal una palabra, él no se entiende lo que leyó, entonces le digo: "Bueno, regrabalo". Claro. [se ríe]. Claro, son procesos. Pero eso que parece que es algo tan automático, no es tan así. Todo tiene su proceso. Todo. (Ana, comunicación personal, 11 de noviembre de 2019) (cursivas nuestras)

Y, bueno, esto también. Para comunicarse, ellos van haciendo procesos. Saber adónde van a presionar para audio, dónde van a presionar para mayúsculas, para minúsculas, o para abrir un correo... También, es todo un proceso. Crear el correo, tener su cuenta, su clave. Son todos procesos. No es que automáticamente apretás un botón y ya está. Son procesos que también los van evolucionando. (Ana, comunicación personal, 11 de noviembre de 2019) (cursivas nuestras)

En estos tres fragmentos distintos Ana da cuenta de aquello que se hace exclusivamente a través de TIC (teléfonos móviles y WhatsApp en particular), y que implica un uso de estas herramientas en Modo Transformación. Se piensa un contenido de enseñanza y una forma para abordarlo que demanda una 
María Rosa Brumat/Diego Agustín Moreiras Prácticas de enseñanza en la modalidad domiciliaria:

Cruces con la educación rural y el uso de TIC Revista Xihmai XVI (31), 39-74, enero-junio 2021

dimensión comunicacional fundamental: qué quiero decir, a quién tengo que decírselo (enviárselo) y cómo debo hacerlo para que sea claro para quien lo recibe. Sumado a esto, Ana agrega una dimensión reflexiva que permite que sea el/la estudiante quien decida sobre estas cuestiones y pueda sopesar su propio proceso de aprendizaje.

Finalmente, deseamos mencionar las estrategias que Ana implementa cuando las familias de las/os estudiantes con quienes trabaja no cuentan con el acceso a computadoras, dispositivos móviles o conexiones estables a internet. El trabajo en estos casos se realiza a través de su propio teléfono, con la conexión móvil también garantizada por ella, o con estrategias como la que relata a continuación:

A: Sí. La otra que yo hago es, si ellos no tienen para abrir algo en internet, yo hago captura y se los mando por mensaje de WhatsApp, que eso sí les llega. Y, entonces, ellos desde ahí pueden abrir la imagen. Entonces, yo les llevo la investigación y se los mando por WhatsApp, para ir acortando los tiempos de tarea en el domicilio. ¿Me entendés? Yo se los explico, todo. Les llevo un cuadro, todo, por medio de una captura (Ana, comunicación personal, 11 de noviembre de 2019) (cursivas nuestras)

De acuerdo al tipo de actividad que se trate, el Modo involucrado en estos casos en los que las familias no tienen los recursos tecnológicos y de conexión podrá ser uno u otro; no obstante, resulta una continuidad en las prácticas de Ana la implementación de las estrategias necesarias para garantizar el proceso de aprendizaje de las/os estudiantes con quienes trabaja. Queríamos cerrar este apartado con esta reflexión, ya que consideramos condensa los objetivos de la modalidad, las dificultades del trabajo en ella, así como las estrategias para resolverlas.

\section{Reflexiones finales y desafíos}

Hemos presentado la experiencia de trabajo de una docente de nivel primario de modalidad domiciliaria y hospitalaria que trabaja con alumnos de una escuela rural. Una práctica docente atravesada por múltiples condicionamientos y por el uso de recursos TIC para la enseñanza y aprendizaje con sus alumnos.

La potencia de la experiencia que analizamos, a nuestro juicio, es que la docente hace uso de las herramientas a su alcance; busca potenciar el trabajo de las/os estudiantes y las interacciones con sus pares y docentes de la escuela Xihmai 68 
María Rosa Brumat/Diego Agustín Moreiras Prácticas de enseñanza en la modalidad domiciliaria:

Cruces con la educación rural y el uso de TIC Revista Xihmai XVI (31), 39-74, enero-junio 2021

a la que pertenecen; asume la formación para el uso de TIC como parte de su tarea (y una parte de la que disfruta); y se apropia diferencialmente del concepto de aula ampliada otorgándole sentido propio, además de los que Sagol inscribe en ese concepto.

Los análisis provisorios que hemos compartido sitúan reflexiones en torno a tres cuestiones que queremos plantear y que cobran sentido en el contexto en el que escribimos este artículo, signado por la pandemia de COVID-19 que nos atraviesa como sujetos y en nuestro trabajo docente. Estas cuestiones tienen que ver con repensar la clase, repensar las prácticas docentes y repensar la formación docente.

Repensar la clase. La experiencia que hemos recuperado nos muestra que las prácticas pedagógicas no reconocen un ámbito delimitado en el espacio del aula ni por ciclos lectivos en lo temporal; a su vez, los sucesos, procesos y relaciones en que se sostiene lo pedagógico se han ampliado. La clase podría repensarse en función de la heterogeneidad de conocimientos, tiempos, lugares y sujetos, para construir propuestas que potencien los procesos educativos y sean significativas para los sujetos involucrados: alumnos, docentes y también las familias, que en la modalidad domiciliaria son parte del proceso escolar y tradicionalmente son percibidas fuera del proceso. Reconocer la diversidad, heterogeneidad y desigualdades en estos procesos nos permite reconocer otros espacios y vías de intercambios y aprovechar las potencialidades de las TIC, construyendo nuevas prácticas y nuevos sentidos.

El concepto de aula ampliada es potente a la hora de pensar y proponer ampliar los límites físicos de una clase, el uso y disponibilidad y acceso a contenidos y soportes digitales, la forma de circulación del conocimiento, la conexión con otros en sentidos multidireccionales. Genera un espacio público en las aulas que rompe ese circuito más individual entre docentes y alumnos, convirtiendo un aula en red. En el caso de la experiencia que compartimos, esta maestra amplía esta comunicación con sus alumnos y la hace un poco más pública, al incluir a otros alumnos, otros docentes, e incluso las familias.

Repensar las prácticas docentes. La experiencia compartida nos permite repensar las prácticas docentes, su complejidad, su contextualización, su historicidad, su dimensión ética y política. Experiencias como la de Ana cuestionan la idea de una práctica docente, de un docente; la idea de que todas 
las prácticas son iguales o similares y que de igual manera, los docentes también lo son.

Cada docente se apropia de las TIC y de sus usos de maneras diferentes y las incorporan en sus prácticas a su manera, según su formación, experiencia y contexto. El acceso a fuentes, recursos, contenidos, herramientas y aplicaciones de información seguramente conduce a los docentes en un camino de búsquedas y a redefinir ciertas prácticas y acciones consideradas habituales; significa también, ubicarse en el lugar de la pregunta, la búsqueda, la incertidumbre más que de las certezas y de las rutinas cómodas sin cuestionamientos.

Repensar la formación de los docentes. Sin duda, los puntos anteriores también nos llevan a pensar sobre los procesos formativos de los docentes, ya sea en formación inicial como en formación continua o permanente.

En relación al uso de las TIC, además de estar integrado con lo pedagógico y lo disciplinar, un uso adecuado de la tecnología en la enseñanza requiere del desarrollo de un conocimiento complejo y contextualizado. "Estas conclusiones demandan una mayor implicación y formación del profesorado para un trabajo coordinado, y el uso de las TIC en conexión con los centros educativos, para propiciar una educación inclusiva." (Palomares-Ruiz et al., 2016, p. 1507). Lo mismo señalan Serrano y Prendes (2014) en términos de la formación inicial de docentes para la modalidad domiciliaria y hospitalaria.

Todo lo anterior implica una forma de trabajo colaborativo, que si bien, se viene difundiendo y enseñando en la formación inicial en los últimos tiempos, aún encuentra tradiciones y prácticas arraigadas en contrario, asentadas en formas de trabajo más individuales y aisladas de los docentes.

Este caso que describimos nos permite repensar las condiciones reales de las prácticas docentes, por ejemplo, en el cruce de modalidades y pensar en una visión amplia del concepto de inclusión escolar en pos de garantizar el derecho a la educación a los sujetos y poblaciones más desfavorecidos. 
María Rosa Brumat/Diego Agustín Moreiras Prácticas de enseñanza en la modalidad domiciliaria:

Cruces con la educación rural y el uso de TIC Revista Xihmai XVI (31), 39-74, enero-junio 2021

\section{REFERENCIAS}

Achilli, E. (2001). Investigación y formación docente. Laborde Editores.

Brumat, M. R. (2010). Políticas educativas en educación rural y formación de maestros en Argentina (2004 - 2009). Políticas Educativas - PolEd, 3(2), 147-156. https://seer.ufrgs.br/Poled/issue/view/1472

Brumat, M. R. (2011). Maestros rurales: condiciones de trabajo, formación docente y práctica cotidiana. Revista Iberoamericana de Educación, 55(4), 1-10. https://doi.org/10.35362/rie5541580

Cragnolino, E. y Lorenzatti, M. C. (2002). Formación docente y escuela rural: dimensiones para abordar analíticamente esta problemática. Páginas Revista de la Escuela de Ciencias de la Educación, 2 (2-3), 63-76. https://revistas.unc.edu.ar/index.php/pgn/article/view/14988

García Álvarez, A. (2014). La educación hospitalaria en Argentina: entre la supervivencia y compromiso social. Foro de Educación, 12(16), 123139. https://doi.org/10.14516/fde.2014.012.016.005

Geertz, C. (1987). La interpretación de la Cultura. Gedisa.

Gómez, M. M. (2011). El sujeto de la Educación Domiciliaria y Hospitalaria: el alumno en situación de enfermedad. Módulo 2. Portal Educ.ar. https://www.chubut.edu.ar/concurso/material/concursos/Educar_suje to_educ_hospitalaria.pdf

González, D. (Coord.) (2017). Guía para la implementación de secundarias rurales mediadas por TIC. UNICEF.

Granados, J. \& Peirats, J. (2016). Proyectos y experiencias TIC en alumnado hospitalizado. Revista científica electrónica de Educación y Comunicación en la Sociedad del Conocimiento, 16(II), 387-407. https://doi.org/10.30827/eticanet.v16i2.11931

León Simón, M. (2017). El valor de las actuaciones pedagógicas en el ámbito hospitalario. Aula, (23), 49-70.

https://doi.org/10.14201/aula2017234970 
María Rosa Brumat/Diego Agustín Moreiras Prácticas de enseñanza en la modalidad domiciliaria:

Cruces con la educación rural y el uso de TIC Revista Xihmai XVI (31), 39-74, enero-junio 2021

Lescano, M. J. (2017). Uso de las TIC en la escuela primaria rural en zonas desfavorables del Valle de Traslasierra, Córdoba. [Tesis de licenciatura, Universidad Siglo XXI]. https://repositorio.uesiglo21.edu.ar/bitstream/handle/ues21/14741/L ESCANO\%20MARIA\%20JULIETA.pdf?sequence $=1 \&$ isAllowed $=$ Y

Lizasoáin, O. (2005). Los derechos del niño enfermo y hospitalizado: El derecho a la educación. Logros y perspectivas. Estudios sobre Educación, 9, 189-201.

Lizasoáin, O. \& Lieutenant, C. (2002). La Pedagogía hospitalaria frente a un niño con pronóstico fatal. Reflexiones en torno a la necesidad de una formación profesional específica. Estudios sobre Educación, 2, 157167.

Martín, M. V. (2016). Desafíos pedagógicos en tiempos de socialidad mediatizada por TIC. III Jornadas de Formación Docente Desafíos y tensiones de la formación docente en los actuales escenarios. Universidad Nacional de Quilmes, Argentina. http://ridaa.unq.edu.ar/handle/20.500.11807/370

Molina Garuz, M. C.; Arredondo Vallejos, T. M. \& González Blanco, J. del P. (2019). Buenas prácticas e innovación en pedagogía hospitalaria. La atención hospitalaria y domiciliaria. Octaedro.

Molina-Pacheco, L. E. \& Mesa-Jiménez, F. Y. (2018). Las TIC en escuelas rurales: realidades y proyección para la integración. Praxis \& Saber, 9 (21), 75-98. https://doi.org/10.19053/22160159.v9.n21.2018.8924

Montesinos, M.P., Sinisi, L. \& Schoo, S. (2010). Aportes para pensar la Educación de Jóvenes y Adultos en el nivel secundario. Un estudio desde la perspectiva de los sujetos. VI Jornadas de Sociología de la UNLP, 9 y 10 de diciembre de 2010. La Plata, Argentina. http://www.memoria.fahce.unlp.edu.ar/trab eventos/ev.5556/ev.555 $\underline{\text { 6.pdf }}$

Ortiz, C. (1999). Formación de los profesionales del contexto hospitalario. Profesorado, revista de currículum y formación del profesorado, 3 (2), 105-120.

Xihmai 72 
María Rosa Brumat/Diego Agustín Moreiras Prácticas de enseñanza en la modalidad domiciliaria:

Cruces con la educación rural y el uso de TIC Revista Xihmai XVI (31), 39-74, enero-junio 2021

Palomares-Ruiz, A., Sánchez-Navalón, B. \& Garrote-Rojas, D. (2016). Educación inclusiva en contextos inéditos: la implementación de la Pedagogía Hospitalaria. Revista Latinoamericana de Ciencias Sociales, Niñez y Juventud, 14 (2), 1507-1522.

Peirats, J., Granados, J. \& Morote, D. (2017). Avances de la investigación en educación y TIC en aulas hospitalarias. Educatio Siglo XXI, 35(3), 6584. https://doi.org/10.6018/j/308901

Requena, M. L. (2011). Prácticas educativas con niños internados en una escuela hospitalaria del conurbano bonaerense. IX Jornadas de Sociología. Facultad de Ciencias Sociales, Universidad de Buenos Aires. https://www.aacademica.org/000-034/356

Sagol, C. (2013, febrero 7). Aulas aumentadas, lo mejor de los dos mundos. [Texto en un blog] Educ.ar.

https://www.educ.ar/recursos/116227/aulas-aumentadas-lo-mejorde-los-dos-mundos

Sánchez, L. E. \& Navarro, M. J. G. (2015). Secundarias rurales mediadas por tecnologías de la información y la comunicación en el norte de Argentina: democratización, inclusión y problemas éticos. Innovación educativa, 15 (69), 37-56.

Serradas Fonseca, M. (2015). La pluridimensionalidad del rol del docente hospitalario.Educ@ción en Contexto, 1(2), 38-55.

Serrano Sánchez, J. L. y Prendes Espinosa, M. P. (2014). TIC para la mejora educativa en aulas hospitalarias. Pixel-Bit. Revista de Medios y Educación, 45, 23-36.

Serrano Sánchez, J. L. y Prendes Espinosa, M. P. (2015). Integración de TIC en aulas hospitalarias como recursos para la mejora de los procesos educativos. Estudios sobre educación, 28, 187-210. https://doi.org/10.15581/004.28.187-210

Souto, M. (1996). La clase escolar. Una mirada desde la didáctica de lo grupal. En Camilloni, A. W., Davini, M.C., Edelstein, G., Litwin, E., Souto, M. \& Barco, S. Corrientes didácticas contemporáneas. pp. 119-139. Paidós. 
María Rosa Brumat/Diego Agustín Moreiras Prácticas de enseñanza en la modalidad domiciliaria:

Cruces con la educación rural y el uso de TIC Revista Xihmai XVI (31), 39-74, enero-junio 2021

Tamargo, C. y Carniglia, E. (2020). Maestras y TIC en escuelas ruralizadas: claves del acceso en la pampa cordobesa. UniRío Editora.

Terigi, F. (Comp.) (2006). Diez miradas sobre la escuela primaria. Siglo XXI.

Twining, P. (2002). Conceptualising Computer Use in Education: introducing the Computer Practice Framework (CPF). British Educational Research Journal, 28(1), 95-110. https://doi.org/10.1080/01411920120109775

Zattera, O. (2017). Aportes para la elaboración de un régimen académico para el ámbito rural bajo la modalidad mediada por TIC. Secundarias Rurales mediadas por TIC. UNICEF.

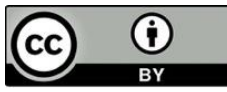

Este texto está protegido por una licencia CreativeCommons 4.0.

Usted es libre para compartir — copiar y redistribuir el material en cualquier medio o formatoy adaptar el documento - remezclar, transformar y crear a partir del material - para cualquier propósito, incluso para fines comerciales, siempre que cumpla la condición de:

Atribución - Usted debe dar crédito de manera adecuada, brindar un enlace a la licencia, e indicar si se han realizado cambios. Puede hacerlo en cualquier forma razonable, pero no de forma tal que sugiera que usted o su uso tienen el apoyo de la licenciante.

\section{Xihmai 74}

